\title{
IRSETCONF
}

\section{APPLICATION OF GEOMIMICRY TO ENGINEERING PROBLEMS: \\ GILSONITE AS A SOLUTION TO LEAKY WELLBORES}

\author{
William Daniel, Mileva Radonjic \\ Oklahoma State University, Chemical Engineering, 420 Engineering North, \\ Stillwater OK,74078, USA
}

\begin{abstract}
As complexity of wells, environmental regulations and the need to be as economically efficient as possible in the petroleum industry increases, it is more prevalent than ever to ensure and maintain wellbore integrity. The purpose of the cement sheath is to maintain wellbore integrity by providing total isolation between surrounding formations and the wellbore. One factor opposing the purpose of a cement sheath is hydrocarbon migration through a micro-annulus located at either the cement/casing interface or the cement/formation interface. Hydrocarbon migration hazards can be as minor as a few psi increase at surface to total blowout which in turn can be timely to repair, if possible, and create unwanted environmental concerns which ultimately effect economic returns. This study focuses on the use of a wellbore cement additive: Gilsonite as a potential agent in the mitigation of micro-annular flow through its unique affinity to hydrocarbons. Gilsonite's affinity and potential to absorb hydrocarbons in the cement matrix is analyzed thoroughly through microstructural analysis of hydrocarbon interaction with Gilsonite grains. The goal of this project is to provide a proof of concept for further microstructural analysis of Gilsonite's ability to mitigate microannular flow. To accomplish this, experimentation was broken into two sperate phases. Phase 1 consists of experimentation on pure Gilsonite to gauge if there was an affinity between Gilsonite and hydrocarbons, while Phase 2 consists of experimentation on Gilsonite rich cement.
\end{abstract}

Keywords: geomimicry, wellbore-cement, gilsonite, microstructure 


\section{IRSETCONF}

\section{Introduction}

Gas intrusion, known as micro-annular flow, through the cement filled annulus has the potential to create pathways for formation fluids to flow through the cement sheath between formations or to the surface. This unwanted migration of fluids is not only dangerous but can be costly to operators by negatively affecting drilling and production conditions with potential to cause a total blowout (Dusseault et al. 2000). Pathways for fluid to migrate through the well into the annulus pressurizes the well rendering it unsafe for production, which can ultimately cause major safety and economic issues for the operator (Kupresan et al. 2014). This failure could also result in premature water production which can limit the economic life of the well. Remedial cement jobs can in some cases resolve this issue, but at the cost of more time which equates to higher costs thus decreasing total monetary profit. Novel technologies, such as mechanical manipulation of the casing are being evaluated as a faster option (Radonjic \& Kupresan, 2015). Mitigation to gas intrusion could be achieved using self-healing cement additives.

Self-healing cement additives have the potential to avoid remedial cementing or plug and abandonment of the wellbore by automatically sealing annular pathways after being exposed to unwanted hydrocarbons (Langley et al. 2018). The additives remain dormant in the cement sheath until hydrocarbon migration occurs. Once exposed to hydrocarbons a reaction occurs, expanding the cement and re-establishing an annular seal preventing any future hydrocarbon migration (Le Roy-Delage et al 2010). The focus of this study is a self-healing cement additive known as Gilsonite.

Gilsonite is a naturally occurring, high purity, solid hydrocarbon mined from the Uinta Basin of Utah and Colorado (Boden, 2014). First introduced in the petroleum industry as a lost circulation material for water-based drilling fluids and later utilized as a low density lost circulation cement additive primarily focusing on minimizing borehole collapses in water sensitive shales (Slagle \& Carter, 1959). Gilsonite has one producer, The American Gilsonite Company, and is only found in one location, Unita Basin, Utah. Gilsonite has survived in an environment similar to that of drilled wells which speak to Gilsonite's ability to maintain integrity in wellbore conditions (Davis\& Gillbreath, 2002). Essentially, by incorporating Gilsonite in wellbore cement one can suggest it is re-injecting Gilsonite to an environment that it is not only familiar with but was formed in. 


\section{IRSEETCONF}

The main purpose of cementing is to provide complete zonal isolation between different formations and the surface, as Portland cement hydration produces material with very low permeability (Bensted \& Barnes, 2002). Gas intrusion into the cement filled annulus can lead to the development of pathways in which formation fluids can flow within the cement to either neighboring formations or the surface. This flow can occur in the casing string, or in liners where gas can emerge at the liner hanger which leads to its circulation out of the well. Remediation of this problem can be time consuming and costly, requiring remedial cement measures such as squeeze cementing until there is no more observed migration of unwanted hydrocarbons. Cement squeezes are difficult to perform correctly with a low rate of success. Self-healing cement (SHC) is a responsive material, where the self-repair mechanism is triggered when hydrocarbons make contact with this material. The main proponent of this technology is that it is self-activated, once exposed to hydrocarbons expansion occurs sealing off areas that were previously exposed to micro-annular flow. Self-healing cements can automatically repair when micro annulus or internal cement cracks are created, thus, repairing and maintaining the integrity of the cement sheath thus allowing it to maintain its functionality. SHC's provide long term durability to a cement sheath repairing cement sheath integrity without the need of manual well intervention. In addition, SHC act just as regular cement if there is no exposure to hydrocarbons. Reduced costs of cement remediation and lost circulation loss in cement integrity while also the potential to improve productive life of the make using SHC an economical and time efficient decision if applicable. (Langley et al. 2018).

It is important to note that the concept of SHC does not preclude the importance of good cement practice, but rather improves the ability to mitigate micro annular fluid migration. When choosing a SHC it is imperative that machinal properties and self-healing properties are both optimized in order to maintain the highest integrity for the cement sheath. Modern completion methods can expose the cement sheath to extreme pressure and temperature cycles and the related stress associated with casing expansion and contraction, incurring damage to the cement structure down hole (Dusseault et al. 2000. The industries perspective has evolved due to the influx of more advanced drilling which uses uniaxial compressive strength to qualify the strength of a cement system. A cement that can withstand substantial pressure and temperature change is key when preparing a slurry to be placed downhole.

1957 was the first documented use of Gilsonite as a cement additive, primarily used in lost circulation zones as lost circulation material due to Gilsonite's low specific gravity of 1.07. 


\section{IRSETCONF}

(Boden, 2014). Gilsonite's particle size distribution, impermeability, excellent bridging properties, corrosive and acidic resistance, and low water requirements produce a slurry that has high compressive strengths compared to other slurries with similar weights. Although Gilsonite is a lightweight material it is not porous. That coupled with its impermeability, Gilsonite rich cement is protected against premature slurry dehydration. Additionally, Gilsonite can withstand bottom hole temperatures greater than $350^{\circ} \mathrm{F}$.

A 1959 study conducted by Slagle and Carter sought to compare the specific properties of Gilsonite rich cement to other slurries with different additives such as diatomic earth materials, bentonite, expanded perlite at equal densities (Slagle \& Carter, 1959). Of these studies, Gilsonite performed highest in compressive strength testing under conditions of 100 $-140{ }^{\circ} \mathrm{F}$ and up to $3000 \mathrm{psi}$. Slagle and Carter were also able to confirm that Gilsonite samples under atmospheric and 3000 psi showed no measurable difference, thus showing there is no void space in Gilsonite.

High compressive strength and the ability to maintain integrity at elevated temperatures make Gilsonite an ideal candidate for not only a cement additive but also a component of a SHC (Didier et al, 2017). Most SHC are only considered to be a short-term solution and most effective while in slurry form. A SHC with an additive such as Gilsonite may have more longterm durability as an agent to mitigate micro-annular flow well after the cement job is finished.

\section{Methods}

The experimental procedure for this research can be broken down into two phases. Phase 1 consists of experimentation on pure Gilsonite to gauge if there was an affinity between Gilsonite and hydrocarbons, while Phase 2 consists of experimentation on Gilsonite rich cement. A detailed table of cement slurry compositions can be found in table 3 in Appendix A. Following Phase 1 and 2 analysis, a conclusion and recommendation for further research will be discussed.

Phase 1: Pure Gilsonite was finely ground using a mortar and pestle before being subjected to micro-structural analysis. Fourier Transform Infrared (FTIR) spectra were collected with a Nicolet iS50 FT-IR Spectrometer equipped with two research grade infrared spectrometers. FTIR was used to examine if there was any $\mathrm{CO}_{2}$ absorption by Gilsonite at pressures up to 400 psi. FTIR provides an infrared spectrum of absorption in either a solid, liquid or gaseous 


\section{IRSEETCONF}

material by collecting high-spectral resolution data over wide spectral ranges. Thermal Gravimetric Analysis (TGA) was used to measure mass change over time under constant exposure to $\mathrm{CO}_{2}$ for two hours at a constant temperature of $86^{\circ} \mathrm{F}$ and then repeated at 122 ${ }^{\circ} \mathrm{F}$.

Phase 2 of this research was conducted on Gilsonite rich cement cores containing varying amounts of Gilsonite ranging from 2.5,5 and 7.5\% Gilsonite by weight of cement. All cement slurries were made to be $13.2 \mathrm{ppg}$ to ensure consistency during testing. All cement used in this research was Haliburton Class $\mathrm{H}$ cement mixed in a Waring Laboratory blender per API recommended procedure (API 2013). Mixing was conducted using a 4-liter, 3.75 horsepower Waring laboratory blender. Initially, bentonite was mixed with deionized water at 16,000 rpm for 5 minutes. After, Class $\mathrm{H}$ cement and Gilsonite were added and mixed for an additional 35 seconds at 20,000 rpm (for neat cement Gilsonite was not added). Following mixing, cement slurries were poured in $3 \times 1$ inch cylindrical brass molds. Samples were kept as atmospheric conditions for 24 hours before being removed from molds and submersed in a solution of deionized water and calcium hydroxide to a $\mathrm{pH}$ of $\sim 13$. The cement cores in the deionized water and calcium hydroxide solution were the placed in an environmental chamber kept at constant temperature, $70^{\circ} \mathrm{C}\left(158^{\circ} \mathrm{F}\right)$, and humidity of $100 \%$ for 21 days. After this time the samples were removed and place in a $0 \%$ humidity oven at a constant temperature of $70^{\circ} \mathrm{C}$ $\left(158^{\circ} \mathrm{F}\right)$ for 24 hours to completely dry the samples in preparation for testing.

Helium-gas Porosimetry was conducted on each core before and after exposure to $\mathrm{CH}_{4}$. An Ultragrain GrainVolume UGV-200 porosimeter was used to collect porosity measurements. The UGV-200 incorporates Boyle's Law helium gas expansion porosimetry in which the core is placed in a known volume with a known pressure then exposed to $10 \mathrm{cc}$ of helium gas.

SEM images with EDS analysis were created using a FEI Quanta 3D FEG/SEM with dualbeam focused ion beam microscopy. SEM imaging was completed at $20 \mathrm{KV}$ and $27 \mathrm{pA}$ at 3 different magnifications for both nonexposed and exposed 7.5\% Gilsonite BWOC. These magnifications range from 100x - 3500x. SEM imaging provides high resolution images of the Gilsonite interaction in the cement structure before and after exposure to $\mathrm{CH}_{4}$. SEM sends high focused energy electron beams at the surface of the sample. Interactions between the electrons and the sample create backscatter electrons and X-rays to display topography and composition. Cores exposed to $\mathrm{CH}_{4}$ for 24 hours using a flow through device. Cores were placed inside a 1 inch in diameter rubber sleeve that had a thickness of 1.75 inches. The rubber sleeve was then put in a 1.75 inch in diameter rubber sleeve with thickness of .25 inches sealed the 24 inches 


\section{IRSEETCONF}

in length plastic housing forcing $\mathrm{CH}_{4}$ to flow through cement cores. $\mathrm{CH}_{4}$ was flowed through the cores and into a graduated cylinder filled with $\mathrm{H}_{2} \mathrm{O}$ to dissolve in water.

\section{Results}

\section{Fourier Transform Infrared Analysis (FTIR)}

Fourier transform infrared spectroscopy is a formidable tool in creating a comprehensive view of the composition and structure/ composition of materials [10]. Alternatively, FTIR can be utilized to observe the absorbance of a material under a given pressure.

As shown in figure 1 Gilsonite was exposed to C02 under pressures varying from 0 psi to 1200 psi $(0,50,100,400$, and $1200 \mathrm{psi})$ with the $\mathrm{x}$ axis representing wavelength $\left[\mathrm{cm}^{-1}\right]$ and the $y$ axis showing absorbance. It should be noted that 1200 psi was not used in results due to poor experimental conditions and leakage observed at that respective pressure. According to the National Institute of Standards and Technology (NIST) for $\mathrm{CO}_{2}$ absorption, if any, will be observed in two major absorption bands. These two bands can be observed in figure 6 in Appendix A. The range of the bands are as follows: $600 \mathrm{~cm}^{-1}$ and $745 \mathrm{~cm}^{-1}, 2250 \mathrm{~cm}^{-1}$ and 2400 $\mathrm{cm}^{-1}$. FTIR spectra on Gilsonite at all pressures showed 3 major absorption bands. The first band can be observed at $668.22 \mathrm{~cm}^{-1}$, the second band between the range of $2287 \mathrm{~cm}^{-1}$ and $2391.34 \mathrm{~cm}^{-1}$ and the third band between $2786.68 \mathrm{~cm}^{-1}$ and $2991.10 \mathrm{~cm}^{-1}$.

The broad absorption band between $2287 \mathrm{~cm}^{-1}$ and $2391.34 \mathrm{~cm}^{-1}$ is the most conclusive evidence that Gilsonite was readily absorbing $\mathrm{CO}_{2}$. It is important to note that this absorption was observed at 0 psi meaning that at ambient pressure Gilsonite was absorbing $\mathrm{CO}_{2}$ which, strongly suggests that Gilsonite does have an affinity to hydrocarbons. The Absorption band at $2786.68 \mathrm{~cm}^{-1}$ and $2991.10 \mathrm{~cm}^{-1}$ suggests that $\mathrm{C}-\mathrm{H}$ stretching of O-rings is occurring due to band peaks observed at these wavelengths. The FTIR data collected closely represents the FTIR data from the National Institute of Standards and Technology providing conclusive evidence that Gilsonite is readily absorbing $\mathrm{CO}_{2}$. Understanding that there is absorption between Gilsonite and $\mathrm{CO}_{2}$ is key in moving forward with the viability of Gilsonite as a $\mathrm{SHC}$ additive and mitigation tool against microannular flow. 


\section{IRSETCONF}

It can be observed that a larger amount of absorption is seen as the pressure increases. While the increase in absorption is likely caused by the increase in pressure, it is common to have increased pressure on the cement in wells with sustained casing pressure. A previous study on sustained casing pressure in 26 different wells measured the frequency of sustained casing pressure. Results of this study showed pressure reaching 1000 psi in production and intermediate casing while reaching $500 \mathrm{psi}$ in surface and conductor casing. While it is evident that Gilsonite does absorb $\mathrm{CO}_{2}$ with and without pressure, sustained casing pressure could potentially contribute to the absorption of hydrocarbons in Gilsonite.

Figure 1: FTIR Gilsonite from wavelength of $650 \mathrm{~cm}^{-1}$ to $3500 \mathrm{~cm}^{-1}$. Absorption bands can be observed at 3 separate peaks that are consistent with that of $\mathrm{CO}_{2}$ absorption peaks

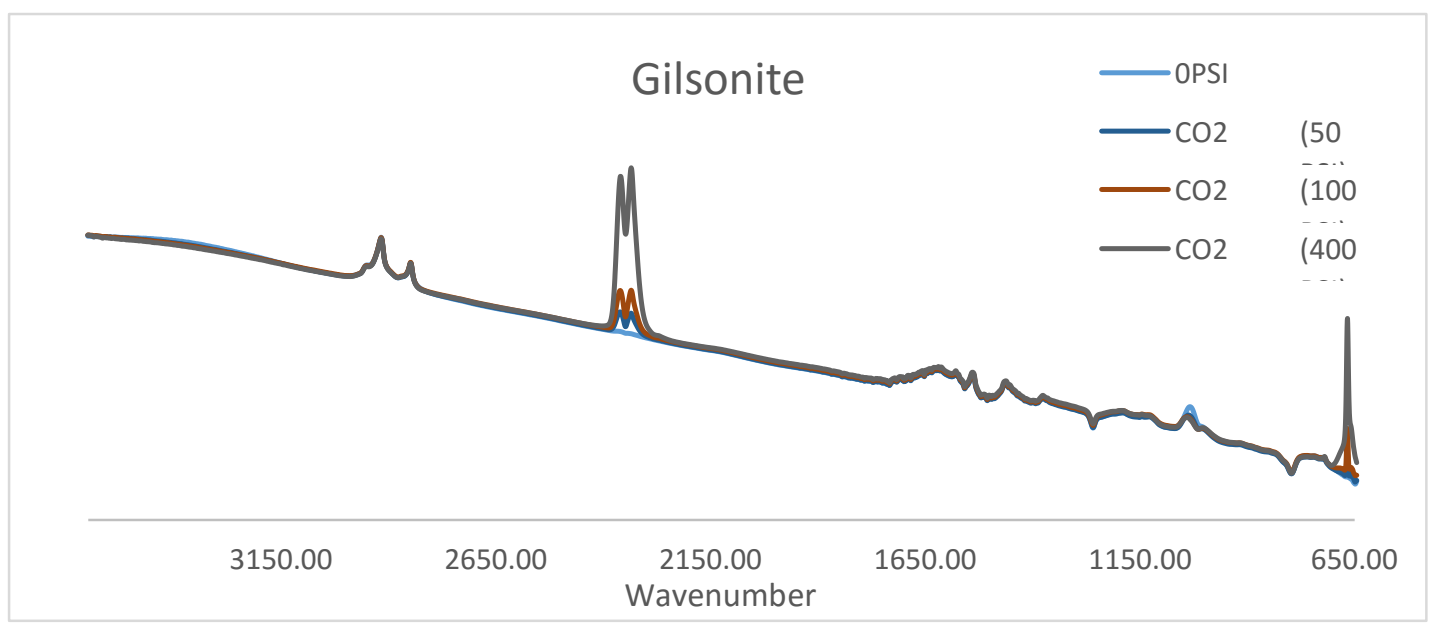

\section{Thermal Gravimetric Analysis (TGA)}

TGA results, seen in Figures $2 \mathrm{~A}$ and $2 \mathrm{~B}$ below, showed an increase in the weight of Gilsonite particles after exposure to $\mathrm{CO}_{2}$ at constant temperatures of $86^{\circ} \mathrm{F}$ and $122^{\circ} \mathrm{F}$. The weight change is measured as weight\% which can by dividing the weight at any time by the initial weight measured prior to running the test. At $86^{\circ} \mathrm{F}$ Gilsonite showed a $0.2454 \%$ weight increase under constant exposure to $\mathrm{CO}_{2}$ while and a $.1956 \%$ increase at $122^{\circ} \mathrm{F}$. The beginning of each run began with a 5 minute "purge" cycle of nitrogen injection. The loss in weight \% during this cycle is most likely attributed to the loss of water or dust mass that was on the 


\section{IRSETCONF}

surface of the Gilsonite particles. The change in weight will be measured from the weight recorded at the end of the "purge" phase to the max peak of the $\mathrm{CO}_{2}$ injection phase.

There is an evident increase in weight $\%$ at both temperatures during $\mathrm{CO}_{2}$ exposure. In the 86 ${ }^{\circ} \mathrm{F}$ test the weight reached its maximum peak at the 79.10 minute. While in the $122^{\circ} \mathrm{F}$ test the weight reached a maximum peak at the 86.96 minute. The $122^{\circ} \mathrm{F}$ test took longer to reach a lower maximum weight than in the $86^{\circ} \mathrm{F}$ which is most likely due to the increase in temperature which could evaporate any impurities in the $\mathrm{CO}_{2}$ that did not at lower temperatures.

While the $86^{\circ} \mathrm{F}$ did reach a higher maximum weight, the difference is negligible and the increase in weight \% for both temperatures can be viewed as the same.

Figure 2: A:Gilsonite Weight \% measured versus time at a constant temperature of $86{ }^{\circ} \mathrm{F}$. An increase in weight \% can be observed once $\mathrm{CO}_{2}$ is introduced; $\mathrm{B}$ : Gilsonite weight \% measured vs time at a constant temperature of $122{ }^{\circ} \mathrm{F}$. An increase in weight \% can be observed once $\mathrm{CO}_{2}$ is introduced
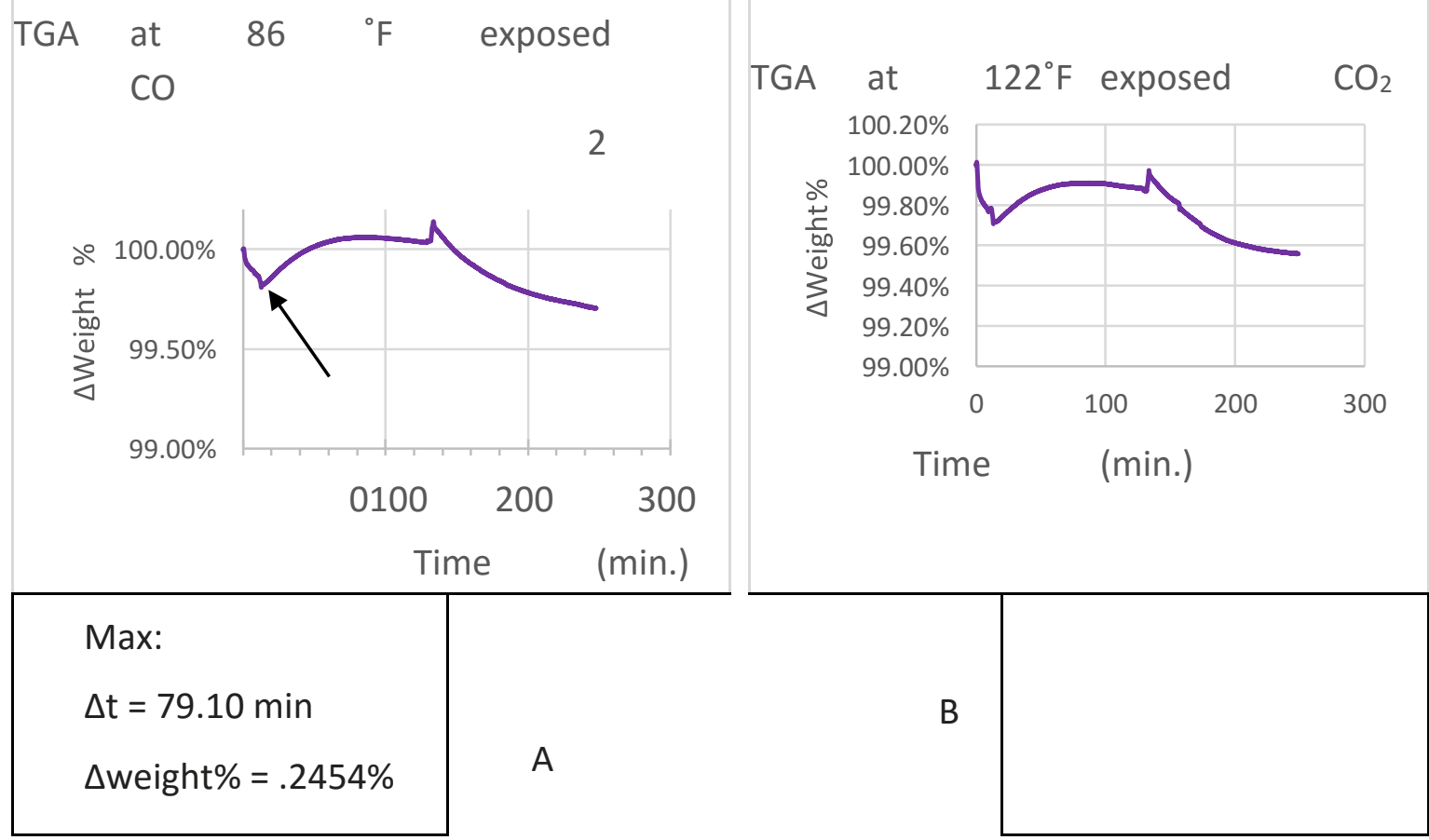


\section{IRSETCONF}

Max:

$\Delta \mathrm{t}=86.96 \mathrm{~min}$

$\Delta$ weight $\%=.1956 \%$

TGA was conducted on samples with a mass of 15.5 and 15.8 micrograms with a mass increase of $0.2454 \%$ and $.1956 \%$ for $86^{\circ} \mathrm{F}$ and $122^{\circ} \mathrm{F}$ respectively. If these samples were conducted on larger mass samples, as they would be in cement cores it is expected that a proportional increase in weight percentage would increase due to an increase in surface area for absorption. TGA testing of Gilsonite under $\mathrm{CO}_{2}$ injection provides a quantitative analysis that Gilsonite does absorb $\mathrm{CO}_{2}$ at ambient and increased temperatures through weight measurement. TGA coupled with FTIR results both show that Gilsonite readily absorbs $\mathrm{CO}_{2}$ under both pressure and temperature. Since absorption has been observed in two different methods, the next step in testing Gilsonite's viability as a SHC additive Is understanding the internal structure and then eventually the interaction of Gilsonite in cement.

\section{Porosimetry}

Porosity measurements were conducted on samples before and after exposure to $\mathrm{CH}_{4}$. It should be noted that these values were calculated with an error margin of $+/-2.5 \%$. Heliumgas porosimetry provides absolute porosity values rather than effective porosity values. Typical cement slurries with a high water-cement ration $(>0.7)$ have high porosity values above $40 \%$ [12]. This corresponds with the data collected on samples with no $\mathrm{CH}_{4}$ exposure. Porosity values decrease with an increase in concentration of Gilsonite. This is evident for both nonexposed and exposed samples. However, the margin of decrease after exposure is much higher for cement that contains Gilsonite compared to neat cement. Gilsonite samples showed a percent decrease of $10.86 \%$ for $2.5 \%$ Gilsonite, $16.44 \%$ decrease for $5 \%$ Gilsonite and $14.86 \%$ decrease for $7.5 \%$ Gilsonite. These decreases are compared to the $4.74 \%$ decrease in neat cement containing no Gilsonite.

The decrease in absolute porosity is substantially higher in samples that contained Gilsonite, most notably $5 \%$ Gilsonite. This data shows that the absorption shown in FTIR and TGA analysis has a significant impact on the physical properties of cement. A decrease in porosity 


\section{İRSETCONF}

upon exposure to hydrocarbons with help prevents further flow of those hydrocarbons to surrounding formations or the surface. This porosity data is important to consider when determining the viability of Gilsonite as a SHC additive. Porosimetry provided quantitative analysis that there is an effect on the physical properties of cement post exposure to hydrocarbons.

\section{Scanning Electron Microscopy (SEM) and Energy Dispersive Spectroscopy (EDS)}

To observe the effects of $\mathrm{CH}_{4}$ exposure on Gilsonite in the microstructure of cement Scanning Electron microscopy (SEM) and Energy dispersive spectroscopy (EDS) were conducted on Gilsonite cores containing 7.5\% Gilsonite by weight of cement. SEM Images of Gilsonite in cement before and after exposure were taken at a high, medium and low magnification for comparison. Figure 3 shows exposed and non-exposed samples of $7.5 \%$ Gilsonite at a magnification of 100x. At this magnification both the exposed and non-exposed samples, Gilsonite is shown in black and evenly distributed throughout the cement matrix with varying size and shape.

Figure 3: SEM image of 7.5\% Gilsonite cement before and after exposure to $\mathrm{CH}_{4}$ at a magnification of 100x. Gilsonite In both, Gilsonite is evenly distributed throughout the cement matrix with varying size and shape.

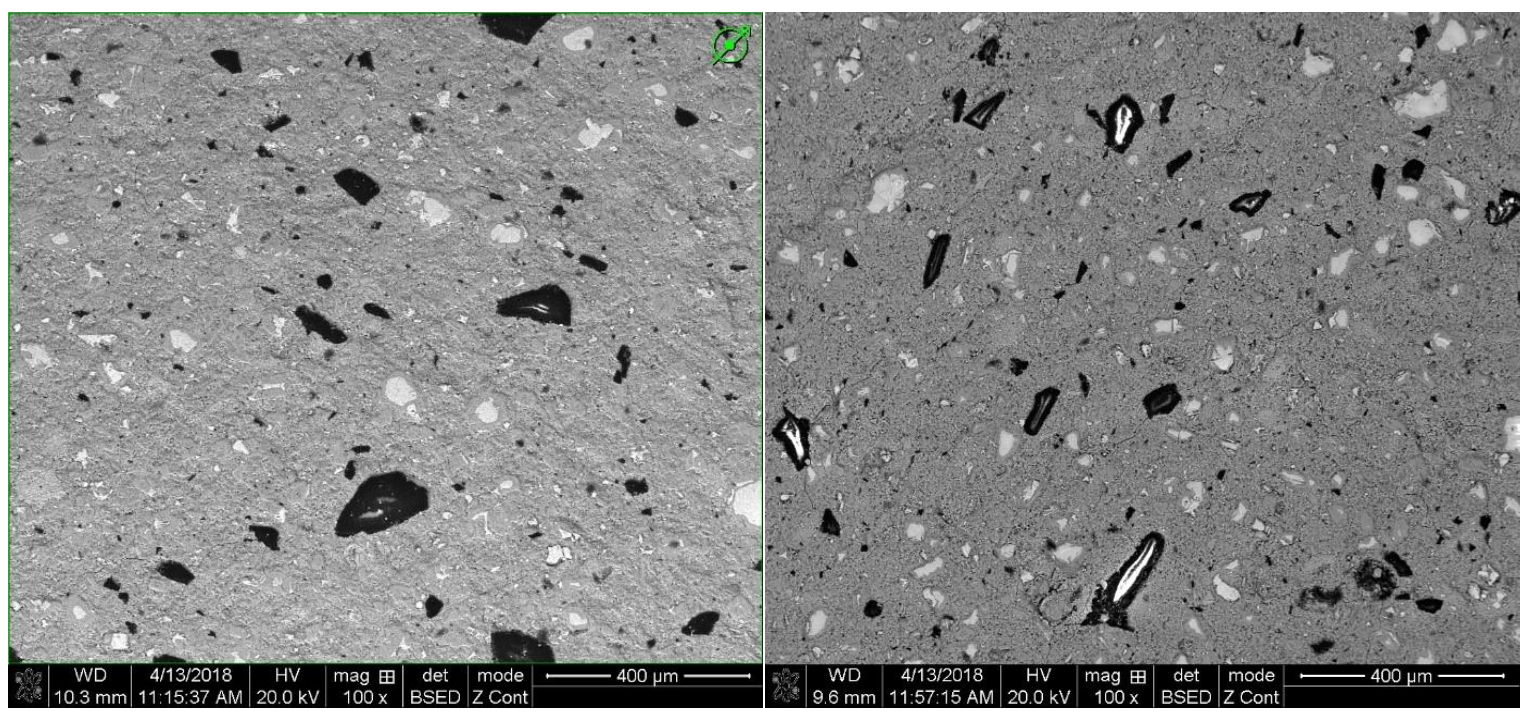




\section{IIRSETCONF}

Figure 4 shows the side by side comparison of a single Gilsonite particle in the cement structure before and after exposure to $\mathrm{CH}_{4}$ at a magnification of $1200 x$ for non-exposed and 1500x for exposed. At this magnification it can be observed that in both images there is no chemical reaction present between the cement and the Gilsonite. This is notable in that the relationship between the Gilsonite pieces and cement is only a physical interaction. Fracturing in the cement can be observed in both cases. These cracks stop at the Gilsonite pieces which is a sign that Gilsonite maintains its structural integrity when cracking in the cement occurs, which can increase overall structural integrity of the cement. At the cement/Gilsonite interface the non-exposed sample seems to have more void space at the cement/Gilsonite interface than the exposed sample in which the Gilsonite particles seems to be flush with minimal void space.

Figure 4: Side by side comparison of a single Gilsonite particle in the cement structure before and after exposure to $\mathrm{CH}_{4}$ at a magnification of 1200x for non-exposed and 1500x for exposed. between Gilsonite

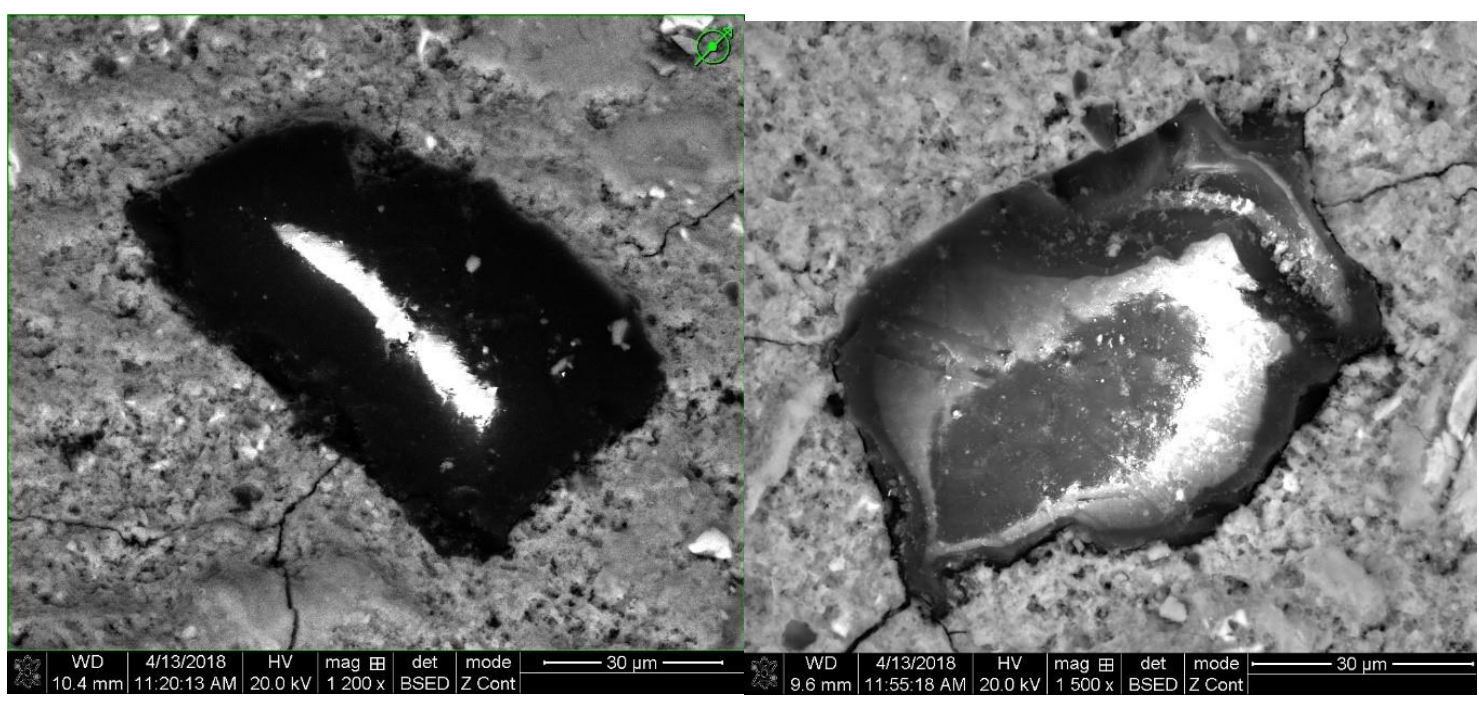




\section{IRSETCONF}

\section{Discussion}

This research's main objective was to provide proof of concept that there is an affinity between Gilsonite and hydrocarbons and its applicability to the petroleum industry. Gilsonite's use as a lost circulation material and wellbore cement additive can be traced back decades, however limited peer reviewed research on Gilsonite in wellbore cement is available. Therefore, microstructural analysis of hydrocarbon interaction with Gilsonite to understand and tests its viability as a self-healing cement additive was conducted. The first objective of this study was Phase 1 experimentation to uncover if, and potentially how much, absorption was possible by cement grains. In order to accomplish this Fourier Transform Infrared (FTIR) and Thermal Gravimetric analysis (TGA) tests were run. Data suggested that there is absorption of carbonbased gasses by the Gilsonite grains, not only under pressure but also with increasing temperature which is important to consider when planning for in-situ conditions below surface.

Once phase 1 results concluded that absorption was present the need to further test mechanical and physical properties of Gilsonite rich cement became relevant. This was accomplished by porosimetry and micro-indentation before and after exposure to $\mathrm{CH}_{4}$. Porosity data suggests that with increasing concentration of Gilsonite in the cement matrix results in a decrease in absolute porosity. A reduction in absolute porosity can lead one to believe that Gilsonite's nonporous structure influences the absolute porosity of the cement matrix leaving less space for unwanted hydrocarbons to potential migrate. Finally, phase 2 testing was concluded with high resolution scanning electron microscopy (SEM) imaging coupled with energy dispersive spectroscopy (EDS). Both tests were run in attempt to visualize Gilsonite grains in the cement matrix and how the chemical composition of the matrix changes with the addition of Gilsonite. Scanning electron microscopy (SEM) images showed a lack of chemical reaction between the Gilsonite and the cement which can lead one to suggest that the Gilsonite/cement relationship is purely physical and there is no concern of a chemical reaction compromising the integrity of the cement.

Further analysis of SEM imaging showed void space in the cement prior to exposure and a lack of void space after exposure at the Gilsonite/cement interface. This is key in visualizing the absorption seen in both FTIR and TGA analysis. This suggests that after exposure to hydrocarbons, Gilsonite can expand into surrounding void space, sealing channels that could transport hydrocarbons to surrounding formations or worst case the surface. To best 


\section{IRSEETCONF}

interpret how this absorption might occur downhole two conceptual schematics, figures 19 and 20, were created to focus on the two interfaces of interest: Cement/Casing and Cement/Formation. These figures are not to scale.

Figure 4: Microannulus present between Cement/Casing and Cement/Formation interfaces. Note,

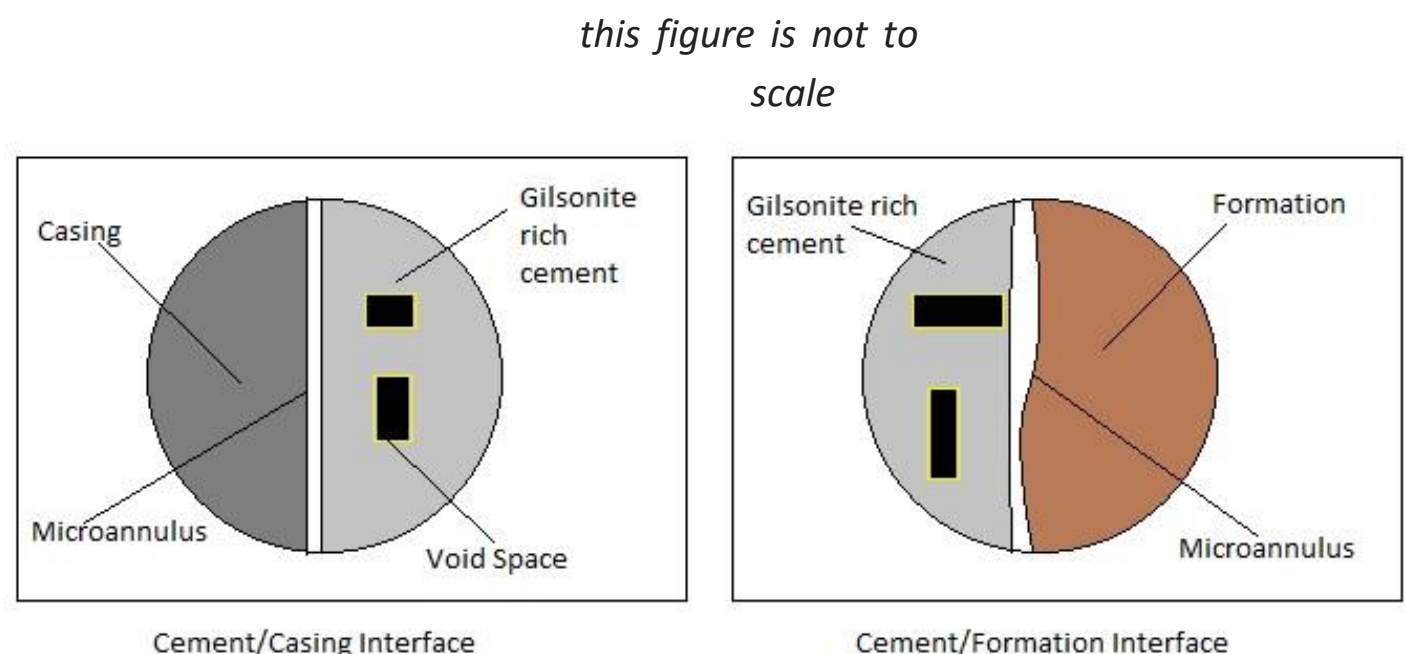

Figure 4 shows a microannulus present at the two interfaces of interest: Cement/Casing and Cement/Formation, prior to hydrocarbon migration. These micro-annuli could have been a product of cement debonding, geological fractures or cement fractures which has left the wellbore and surrounding formations vulnerable to gas migration

Figure 5 illustrates what happens to the interfaces of interest once hydrocarbon mitigation into the cement occurs. Once hydrocarbons contact Gilsonite grains, absorption and expansion into previous void space occurs reducing overall absolute porosity and permeability of the cement. Consider thousands of Gilsonite grains collectively expanding into cracks/fissures and microannular channels causing total cement expansion mitigating microannular flow. This absorption and expansion of Gilsonite grains could cause overall cement expansion, re-sealing the cement/casing or cement/formation interfaces and preventing further mitigation of hydrocarbons. While a perfect reseal is not expect 


\section{IRSETCONF}

Figure 5: Conceptual schematic of mitigation of hydrocarbons migration through Gilsonite expansion as a product of hydrocarbon absorption at Cement/Casing and Cement/Formation interfaces. Note this figure is not to scale

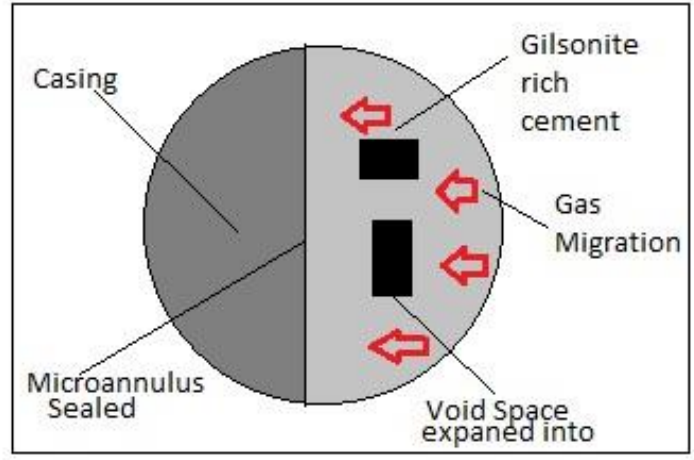

Cement/Casing Interface

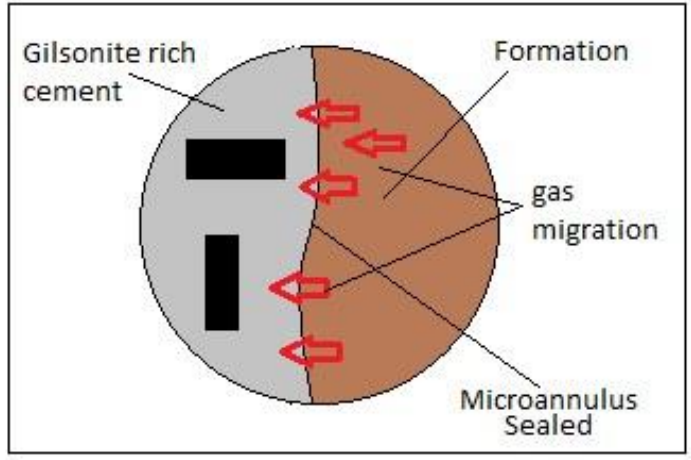

Cement/Formation Interface

With the complexity of wells increasing, either through low pressure formations, depleted formations or offshore the need for a self-healing cement is becoming more and more prevalent. In an industry dominated by efficiency and economic feasibility, application of Gilsonite rich cement can result in maintaining wellbore stability, mitigation of microannular flow to the degree of first in class neat cement, but an increased level of longevity that could last the lifecycle of the well. Gilsonite enriched cement provides a unique hydrocarbon absorption not found in the best neat cements which can substantial economic and environmental impact.

The application of Gilsonite enriched cement is not singular to prevention of microannular flow. The need for adequate well plugs grows proportionally to the number of wells drilled each year. It is key that a well plug can arrest gas flow in wells that experience repressurization while withstanding the geological test of time. Gilsonite, unlike polymers or other cement additive mixtures has proven that it can withstand the tests of geological time because it has lasted thousands of years in its depositional environment making Gilsonite a viable candidate for mitigation of microannular flow. 


\section{IRSETCONF}

\section{Conclusions and recommendations}

- Fourier Transform Infrared (FTIR) showed absorption of $\mathrm{CO}_{2}$ at pressures ranging from ambient to 400 psi

- Thermal Gravimetric analysis (TGA) showed $\mathrm{CO}_{2}$ Absorption at $86^{\circ} \mathrm{F}$ and $122^{\circ} \mathrm{F}$

- Porosity measurements showed decrease in absolute porosity with increasing concentrations of Gilsonite with further decrease in porosity after exposure to $\mathrm{CH}_{4}$

- SEM images show no chemical reaction between cement matrix and Gilsonite. Void space less evident in cores exposed to $\mathrm{CH}_{4}$.

Proof of Gilsonite's potential applicability as a SHC additive can be suggested by the findings of this study. Current remediation methods of microannular flow can be time consuming, which in turn equates to higher costs, dangerous if not detected in time, and not completely effective. Making Gilsonite a logical, cost, efficient, time efficient and a safe alternative to mitigation of microannular flow. Planning and selecting a true $\mathrm{SHC}$ is the best defense against micro-annular flow and Gilsonite provides long term stability for wellbore integrity. Further research needs to be completed to make more confident and definitive claims on Gilsonite's absorption of hydrocarbons and as an agent against microannular flow. The recommendations from this project are detailed in the next section.

To better understand the absorption of hydrocarbons by Gilsonite it is recommended that these same experiments be conducted on a larger time scale, with periods of non-exposure to understand the longevity of this absorption. If long term absorption can be determined, it is recommended that, if possible, a cement/casing and cement/formation interface with micro annuli be produced to scale and exposed to hydrocarbon migration. Another recommendation is to manipulate the Gilsonite grains to all be of the same size and shape with known surface area and then test exposure. If all grains are of equivalent size expansion and absorption on a larger scale can be more easily approximated.

\section{References:}




\section{IRSETCONF}

[1] API 10B-2, (2013). Recommended Practice for Testing Well Cements, American Petroleum Institute Standards, second edition. Washington DC, USA.

[2] Bensted, J., and Barnes, P. (2002). Structure and Performance Of Cements, Taylor \& Francis, New York, USA.

[3] Boden, T., (2014), Utah Still Supplying Gilsonite to the World after 125 Years of Mining, A.G. Company, Editor. January issue.

[4] Davis, N. and Gillbreath, K. 2002. The Many Facets of Gilsonite, American Association of Drilling Engineers, (02-DFWM-HO-38).

[5] Didier, A., Radonjic, M., and Du, H. (2018) The Wellbore Cement Additive, Gilsonite, a Solution to Leaky Gas Wells? Paper ARMA 18-1242 prepared to present at 52nd US Rock Mechanics/Geomechanics Symposium, 17-20 June, Seattle, WA

[6] Dusseault, M.B., Gray, M. N., and Nawrocki, P.A., (2000). Why Oilwells Leak: Cement Behavior and Long-Term Consequences, presented at the SPE International Oil and Gas Conference and Exhibition, Beijing, China, SPE 64733

[7] Kupresan, D., Heathman, J., Radonjic, M., (2014), Casing Expansion as a Promising Solution for Microannular Gas Migration. SPE Drilling \& Completion Journal, 29 (4).

[8] Langley, M., Cleveland, M., Eulberg, J., \& Hudson, M. (2018). Flexible, Self-Healing Cement Eliminates Sustained Casing Pressure in Denver-Julesburg Basin Unconventional Wells. Society of Petroleum Engineers. doi:10.2118/189587-MS

[9] Le Roy-Delage, S., Comet, A., Garnier, A., Presle, J.-L., Bulte-Loyer, H., Drecq, P. P. A., \& Rodriguez, I. U. (2010,). Self-Healing Cement System-A Step Forward in Reducing LongTerm Environmental Impact. Society of Petroleum Engineers. 1doi:10.2118/128226MS.

[10] Nciri, N., Song, S., and Kim, N., (2014). Chemical Characterization of Gilsonite Bitumen. Journal of Petroleum \& Environmental Biotechnology, Vol.10.

[11] Radonjic, M., Kupresan, D., (2014), Mechanical Expansion of Steel Tubing as a Solution to Leaky Wellbores, Journal of Visual Experiments, (93), e52098, doi:10.3791/52098 


\section{IRSETCONF}

[12] Slagle, K.A., and Carter, L.G., (1959). Gilsonite - A Unique Additive for Oil-Well Cements. American Petroleum Institute Standards-API-59-318. 